\title{
Jornalismo digital e colaboração: sinais da desrreterritorialização
}

Vivian Belochio

\section{Resumo}

Este artigo define o território jornalístico institucionalizado e discute a sua transformação nas redes digitais. O texto define a cauda longa da informação, o ProAm e destaca as estratégias comunicacionais do jornalismo nesse contexto. Em seguida, expõe aspectos apurados num estudo de caso de Zero Hora.com, interpretados como sinais da des-re-territorialização no jornal digital.

Sobre • autor Mestre em Comunicação Midiática pela Universidade Federal de Santa Maria (UFSM). Doutoranda em Comunicação e Informação pela Universidade Federal do Rio Grande do Sul (UFRGS). vicabel@terra.com.br

\section{Digital Journalism and collaboration: signs of unterritorialization}

\section{Abstract}

This article defines the territory journalistic institutionalized and discusses its processing in digital networks. The text defines the long tail of information, the Pro-Am and highlights the communications strategies of journalism in this context. Then exposes clearance aspects of a case study of Zero Hora.com interpreted as signs of unterritorialization in the digital newspaper.

Key words:

Digital journalism, Unterritorialization, Pro-Am, Long tail, Zero Hora.com 
O alargamento do território ${ }^{1}$ do jornalismo no ciberespaço é fato notório na contemporaneidade. $\mathrm{O}$ surgimento de diferentes modalidades comunicativas nas redes digitais e a apropriação destas pelas mídias de referência resultaram na renovação das suas possibilidades de ação. O processo parte de remediações (BOLTER; GRUSIN, 2000) e rupturas. Acredita-se que tais transformações marcam a des-re-territorialização (LEMOS, 2006) do jornalismo na ambiência digital, que será discutida no tópico 2.

A incorporação dos sistemas colaborativos nos sites dos jornais de referência ${ }^{2}$ é compreendida como um sinal do fenômeno. Sua inclusão no jornalismo digital vem acontecendo desde a popularização dos meios colaborativos, que acabaram sendo vistos como concorrentes pelas mídias de referência. A rede amadora de informações forma um circuito noticioso diferente do convencional, definido aqui como a cauda longa da informação (ANDERSON, 2006; BELOCHIO, 2008; 2009).

Em adaptação ao cenário descrito, os meios jornalísticos começaram a implantar seções colaborativas nos seus produtos digitais. Com isso, abriram espaço para a produção cooperativa entre profissionais e amadores, isto é, para o movimento Pro-Am. Este último é uma das características da cauda longa, segundo Anderson (2006). O movimento Pro-Am pode estar acontecendo no contexto controlado dos jornais digitais, justamente no interior das suas seções colaborativas. Representa uma alteração interessante da relação entre os jornalistas e as suas fontes, distinta dos padrões vigentes até pouco tempo atrás.

Este artigo define as características do território jornalístico institucionalizado e discute a sua complexificação no ciberespaço. Com este intuito, contextualiza a cauda longa da informação, o Pro-Am e destaca as estratégias comunicacionais do jornalismo nesse contexto. Parte-se do pressuposto de que as seções colaborativas e o Pro-Am representam linhas de fuga das práticas jornalísticas tradicionais. Nesse sentido, elas são capazes de provocar rupturas ${ }^{3}$.

Por fim, são expostos os resultados de uma pesquisa que buscou identificar sinais da des-re-territorialização num meio jornalístico tradicional, a partir da apropriação do modelo da produção colaborativa de notícias. $\mathrm{O}$ texto expõe os principais achados do estudo de caso $^{4}$ do jornal digital gaúcho Zero Hora.com, administrado pelo Grupo RBS, enfatizando especificamente os dados apurados a partir da observação estruturada da sua capa.

\section{A crise do território jornalístico nas redes digitais}

O conceito de território tem definição que ultrapassa a mera consciência sobre localização geográfica e divisão de fronteiras. Análises de Berger e Luckmann (1985), Lemos (2006) e Ortiz (1999) remetem, de maneiras distintas, ao entendimento de que o homem cria relações simbólicas com a realidade, de certa forma moldando o 
mundo para sua vivência. Assim, o território nacional, por exemplo, não é entendido apenas como geográfico. É visto como um conjunto de valores, normas e características que estabelecem um referencial de seu todo. Neste trabalho, o território é compreendido como um espaço simbólico institucionalizado ${ }^{5}$, que possui o seu conjunto de regras, costumes e ética. Trata-se de um ambiente marcado pelo compartilhamento de interesses, de costumes e de condutas reconhecidas e adotadas como padrões de comportamento.

Nesse sentido, o jornalismo também tem um território. Este formou-se historicamente baseado em métodos de produção e transmissão de informações que evoluíram conforme o desenvolvimento tecnológico. Desde os manuscritos noticiosos (BURKES; BRIGGS, 2004) e do chamado "protoperiodismo" (MOMPART; OTTO, 1999) foram criados modelos de produção e distribuição de informações que se transformaram em marcas dos meios informativos. Assim, o jornalismo se estruturou e cristalizou as suas bases produtivas no sistema da comunicação de massa, institucionalizando o seu território de ação.

Acredita-se que o surgimento de fatores de crise, tais como as tecnologias da informação e comunicação (TICs), pode acabar desestabilizando o equilíbrio deste território. A presença e a disseminação de distintas tecnologias na sociedade evidenciam a transformação das formas de representação social (CASTELLS, 1999; ECHEVERRÍA, 1999; LÉVY, 2000). Criam-se, neste ponto, diferentes possibilidades de atuação das instituições e dos indivíduos.

Quando a situação descrita se estabelece, começam a ser repensadas as práticas, os conceitos e as funções delimitadas em cada território ou campo de ação. Em suma, a necessidade da renovação, que emerge com os referidos fatores de crise, provoca tensões na execução das ações e no cumprimento das funções correspondentes ao ambiente real das instituições. Ou seja, os elementos novos podem modificar a vida cotidiana das instituições. O ciberespaço tem essa característica e possibilita/provoca mutações interessantes nos sistemas jornalísticos.

Tais aspectos são marcas do processo de desterritorialização (LEMOS, 2006). Segundo Lemos (2006), ele sucede quando uma nova tecnologia impulsiona a renovação de processos, hábitos e práticas dentro de contextos estabelecidos, podendo desencadear rupturas capazes de alterar a atuação, função e objetivos de determinados campos. A adaptação acaba tendo reflexos nas características dos produtos jornalísticos, já que, a partir do domínio da tecnologia, criam-se diferentes possibilidades para a sua configuração e ocorrem transformações.

Consolidadas as rupturas, posteriormente à desterritorialização, ocorre a reterritorialização, compreendida como a reorganização de um sistema, que mescla características de sua identidade tradicional com distintos parâmetros de funcionamento. Ela acontece após o processo de familiarização de certos campos com as diferentes tecnologias que surgem e são apropriadas por eles. Assim, a reterritorializa-

${ }^{5}$ Berger e Luckmann (1985) definem os territórios simbólicos como a representação da realidade social objetivada, definida como um universo simbólico criado pelos humanos, que se torna um sistema com regras e normas reconhecidas pelos cidadãos. Tal universo passa a dominar a sociedade dentro de sua lógica. Já o processo de institucionalização, segundo os autores, "ocorre sempre que há uma tipificação recíproca de ações habituais por tipos de atores", isto é, sempre que certas ações se transformam em hábitos cotidianos, que se tornam automáticos, quase como regras de comportamento (BERGER; LUCKMANN, 1985, p.79). 
ção sucede depois que ocorre uma adaptação, que as pessoas passam a dominar os elementos propulsores da mudança e que os produtos e formas de trabalho derivados dessa alteração tornam-se cotidianos.

Quando os processos de desterritorialização e reterritorialização se repetem, após um novo ciclo de renovações, ocorre o que Lemos (2006) explica ser o fenômeno de des-re-territorialização. Enfatizando o ciberespaço como elemento chave desse processo, Lemos (2006, p.7) destaca sua potência para "a criação de linhas de fuga em um espaço de controle informacional”. O pesquisador salienta, ainda, que essa mudança de rotas impõe uma dinâmica de readaptações. A modificação das perspectivas de produção e de consumo, além dos fluxos globais informativos, evidencia a necessidade de uma nova adaptação dos produtos e práticas tradicionais à lógica destacada.

Relacionando-se as observações anteriores com o desenvolvimento do jornalismo digital, percebe-se que, atualmente, as tecnologias inseridas no circuito da informação em rede estão provocando novamente a necessidade de adaptações. $\mathrm{O}$ surgimento de sistemas que facilitam a produção e publicação de conteúdos, aliado à abertura dos pólos de emissão, culminou no aparecimento de espaços como blogs e de páginas colaborativas. As tecnologias móveis também abriram diferentes opções de atuação para os indivíduos e para os meios informativos. Assim, foi iniciado novamente um processo de apropriação no jornalismo, que vem experimentando tais recursos.

O ciclo de mudanças pode indicar o início da des-re-territorialização no jornalismo, devido à abertura da possibilidade de transformações nos produtos e nas formas de pensar o fazer jornalístico. As mudanças partem da absorção de tecnologias e modalidades informativas que apareceram na ambiência digital e vem mostrando a sua força. Acredita-se que a sua inclusão no jornalismo digital, com o passar do tempo, pode acabar ocasionando alterações radicais no seu território, desencadeando rupturas.

\section{A cauda longa da informação, o Pro-Am e as estratégias comunicacionais no jornalismo digital}

Aspectos como a popularização e a miniaturização das ferramentas de produção e de publicação são impulsos ao crescimento do processo de participação nas redes. O contato dos cidadãos com as mídias locativas ${ }^{6}$ e com os territórios informacionais ${ }^{7}$ (LEMOS, 2007) também são fatores capazes de estimular a inserção de indivíduos e organizações no ciberespaço, intensificando as iniciativas de colaboração. A conexão generalizada, que segundo Lemos (2003) é o resultado da vulgarização do acesso ao ciberespaço, contribui para a transformação.

Assim, forma-se um diferente circuito de trocas entre os jornalistas e os leitores nas redes digitais. O processo é potencializado pela disponibilização de produtos jornalísticos em bases de dados (BDs)

${ }^{6}$ Segundo Lemos $(2007$ p.1), "as mídias locativas são dispositivos informacionais digitais cujo conteúdo da informação está diretamente ligado a uma localidade. Isso implica uma relação entre lugares e dispositivos móveis digitais até então inédita”.

${ }^{7}$ Instituições e sujeitos podem se fazer presentes no ciberespaço a partir do que Lemos (2007) chama de "território informacional". Este último é definido como "o espaço movente, híbrido, formado pela relação entre o espaço eletrônico e o espaço físico" (LEMOS, 2007, p.12). 
(BARBOSA, 2007) e pela apropriação dos recursos da Web 2.0, que tem como base o aproveitamento da inteligência coletiva (ROMANí; KUKLINSKI, 2007).

Acredita-se que os benefícios das BDs e da Web 2.0, das tecnologias móveis, das mídias locativas e do território informacional (LEMOS, 2007; SILVA, 2008) na produção e difusão de dados por cidadãos e organizações impulsionam uma mudança no padrão do jornalismo digital. A marca mais evidente da fase descrita é a abertura à interferência do público nos materiais noticiosos, que está sendo experimentada nas mídias de referência.

A intensificação das manifestações dos cidadãos no ciberespaço cria um circuito da informação que pode ser relacionado ao que Anderson (2006) define como "cauda longa". Segundo o autor, ela possibilita a valorização dos chamados nichos, "numa era sem as limitações do espaço físico e de outros pontos de estrangulamento da distribuição" (ANDERSON, 2006, p.23). Assim, na era da comunicação digital, é possível atender a necessidades e desejos de públicos específicos por meio das redes, que possuem espaço ilimitado, abrigando, assim, tanto a preferência das massas quanto a das minorias. Com a notícia ocorre a mesma coisa: o que antes era publicado com exclusividade pelas mídias de referência agora divide espaço com as iniciativas dos amadores. O quadro atual pode configurar uma cauda longa da informação.

A caracterização da cauda longa da informação é considerada necessária, para que se entenda como se reformula o mercado informativo nas redes e de que maneira ele pode acabar afetando o território institucionalizado do jornalismo. Entre os pesquisadores que analisam o jornalismo colaborativo, é perceptível a existência de questionamentos sobre a inserção da prática da colaboração no campo jornalístico (FONSECA; LINDEMANN, 2007; GILLMOR, 2005; HEWITT, 2007; PALACIOS; MUNHOZ, 2005; GARCÍA; OTERO LÓPEZ, 2007; BARBOSA, 2007; STORCH, 2008; LÓPEZ, 2008; NOCI; SALAVERRÍA, 2003; MEYER, 2007). Entretanto, eles ainda não chegaram a um consenso sobre quais fatores impulsionam a inclusão dos conteúdos colaborativos nos jornais digitais. A figura mostrada a seguir ilustra a cauda longa adaptada ao cenário informativo:

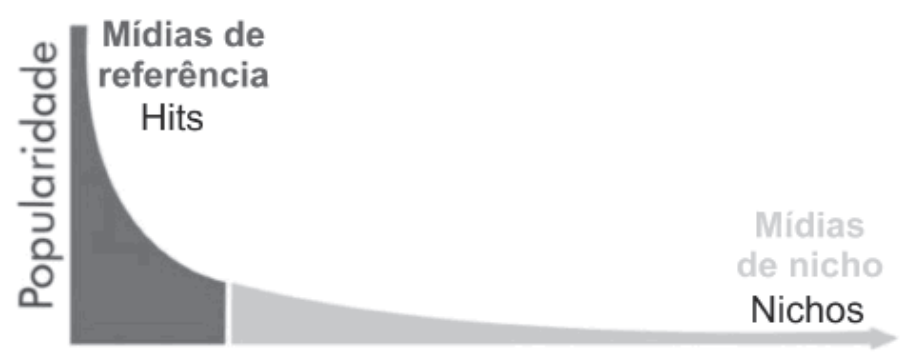

Produtos

Figura 1 - Na cauda longa da informação, as mídias de referência são os hits e os sistemas colaborativos estão entre as mídias de nicho.
Na era da comunicação digital, é possível atender

a necessidades e desejos de públicos específicos por meio das redes abrigando, assim, tanto a preferência das massas quanto a das minorias 
Para entender melhor como se forma a cauda longa da informação, é pertinente observar a sua estrutura no circuito informativo digital, conforme a figura 1. Seguindo o conceito de Anderson (2006), no topo da curva da demanda ficam os chamados hits, ou seja, os produtos mais consumidos, preferidos pela maioria do público. No modelo da cauda longa da informação, esse seria o caso das mídias de referência, que conquistaram credibilidade no decorrer da sua história, tais como jornais, emissoras de TV e rádio e outras marcas mais conhecidas e também atuantes fora do universo digital. Sua presença no ciberespaço é mais uma forma de projeção de seus conteúdos massivos.

$\mathrm{Na}$ cauda, conforme descreve o autor, encontram-se os nichos, aqui entendidos como as variadas mídias que atendem demandas específicas e até personalizadas do público, podendo ter ligação direta com organizações e indivíduos específicos e mantendo o seu foco em assuntos determinados. Aí estão incluídos os meios informativos sustentados por amadores, que não possuem ligação direta com as mídias de referência. Nesse contexto estão os sistemas conhecidos como jornalismo colaborativo, incluindo-se as páginas colaborativas, que são espaços sustentados por amadores, com ou sem controle editorial. Estas coexistem com a mídia tradicional, isto é, convivem com os hits num mesmo espaço. Assim, a variedade de iniciativas que atende aos nichos constitui certa concorrência com os hits.

O cenário constituído na cauda longa da informação obriga os meios jornalísticos de referência a repensarem as suas práticas, com o objetivo de manter a sua popularidade no ciberespaço. O processo é marcado pela apropriação dos sistemas colaborativos na mídia tradicional. A ação se configura como estratégia comunicacional, que visa à inclusão dos meios jornalísticos na cauda longa da informação. Tal estratégia se dá, inicialmente, por ações de remediação (BOLTER; GRUSIN, 2000), isto é, de adaptação das mídias mais antigas às novidades tecnológicas, a partir da sua incorporação aos produtos tradicionais. A adaptação, contudo, pode chegar a modificar certos procedimentos e normas até então vigentes como padrões dominantes, possibilitando, dessa forma, a des-re-territorialização.

Com o processo de remediação, surgiram as seções colaborativas, que foram desenvolvidas com base nos formatos das páginas colaborativas, definidas anteriormente. É o caso de espaços como o Eu Repórter, de O Globo $^{8}$, do Foto Repórter ${ }^{9}$, pertencente ao Estadão.com, do Yo Periodis$t a^{10}$, vinculado ao jornal espanhol El País, e da seção Leitor-Repórter ${ }^{11}$, de Zero Hora.com. O diferencial destas seções é a sua regulamentação interna. As normas adaptam o modelo colaborativo aos critérios de ação das mídias de referência, na tentativa de garantir o controle da situação comunicativa, isto é, de manter seu território equilibrado.

Vale lembrar que os meios de referência tem se apropriado, também, dos modelos do que Primo (2008) define como micromídias digitais. $\mathrm{O}$ pesquisador expande a descrição das micromídias analó-

${ }^{8} \mathrm{http}: / /$ oglobo.globo.com/ participe

${ }^{9} \mathrm{http}: / /$ www.estadao.com. br/ext/fotoreporter/foto_imagens.htm

${ }^{10} \mathrm{http} / / / \mathrm{www} . e l p a i s . c o m /$ participacion

${ }^{11} \mathrm{http}: / /$ www.clicrbs.com.br 
gicas de Thornton (2006), entendendo que, no contexto digital, elas são um "sub-tipo" que "diferencia-se substancialmente da micromídia analógica no que toca o alcance". As micromídias digitais tem maior abrangência porque estão nas redes, ou seja, permanecem disponíveis em escala global. Já é possível visualizar algumas páginas jornalísticas que se apropriaram dos sistemas citados. Em alguns casos, estes aparecem como espaços semelhantes aos modelos comunicacionais propostos em microblogs como o Twitter.

Outro fenômeno da cauda longa que pode estar acontecendo no jornalismo e sendo intensificado nas seções colaborativas é o movimento Pro-Am. Citando experiências da astronomia realizadas com o auxílio de voluntários, Anderson (2006, p.58) define o movimento como o sistema "em que profissionais e amadores trabalham lado a lado". O jornalismo colaborativo e suas configurações no ciberespaço, em formatos de blogs, sites como Wikipedia, Wikinews e OhmyNews, além de outros canais abertos por jornais digitais da grande mídia, evidencia a incorporação da era Pro-Am nos sistemas informativos em rede.

O movimento Pro-Am é considerado uma linha de fuga, ou seja, um fator des-re-territorializante, em relação aos parâmetros tradicionais do jornalismo, mais especificamente no que diz respeito à relação estabelecida entre os profissionais da informação e as suas fontes. É reconhecida a possibilidade de uma alteração nesta relação (PINTO, 2000; MACHADO, 2003; PRIMO; TRÄSEL, 2006). Entende-se que, no ciberespaço, a mudança é impulsionada pelos sistemas colaborativos, que possibilitam, entre outros processos, a ampliação da resolução semântica das informações publicadas na Web (FIDALGO, 2004) e o desenvolvimento do crowdsourcing ${ }^{12}$ (BRIGGS, 2007).

No jornal digital Zero Hora.com, foram encontradas marcas dos processos descritos nos parágrafos anteriores. O próximo tópico descreve aspectos relevantes da pesquisa.

\section{Estudo de caso de Zero Hora.com: observação da capa}

Até aqui foram identificadas mudanças que vem ocorrendo no jornalismo a partir da apropriação das TICs e dos modelos das páginas colaborativas no cotidiano dos meios digitais. Para visualizar sinais destas alterações, foi realizado o estudo de caso do site Zero Hora. com. A observação da capa do jornal digital, que integrou a primeira parte do estudo de caso, será priorizada neste artigo. Isso porque trouxe resultados importantes, que demonstram o Pro-Am, ou seja, linhas de fuga que podem indicar a des-re-territorialização.

A observação estruturada foi aplicada numa amostra de 96 capas, captadas no período de 32 dias, entre 16/12/2008 e 16/01/2009. O que se buscou na amostra foi a frequência da utilização de conteúdos colaborativos e da apropriação do modelo das micromídias digitais.

${ }^{12}$ Segundo Briggs (2007), crowdsourcing significa o "público como fonte de notícias ou conteúdos produzidos por usuários". O termo é compreendido como "quase um sinônimo de investigação ou reportagem compartilhada, colaborativa, distribuída ou em código aberto". Beneficia, então, ao Pro-Am. 
Com esse intuito, foram contabilizadas as chamadas e as manchetes ${ }^{13}$ para as notícias da seção Leitor-Repórter e para os murais ${ }^{14}$. A imagem a seguir mostra o formato das manchetes num quadro verde e o formato das chamadas num quadro de cor laranja:

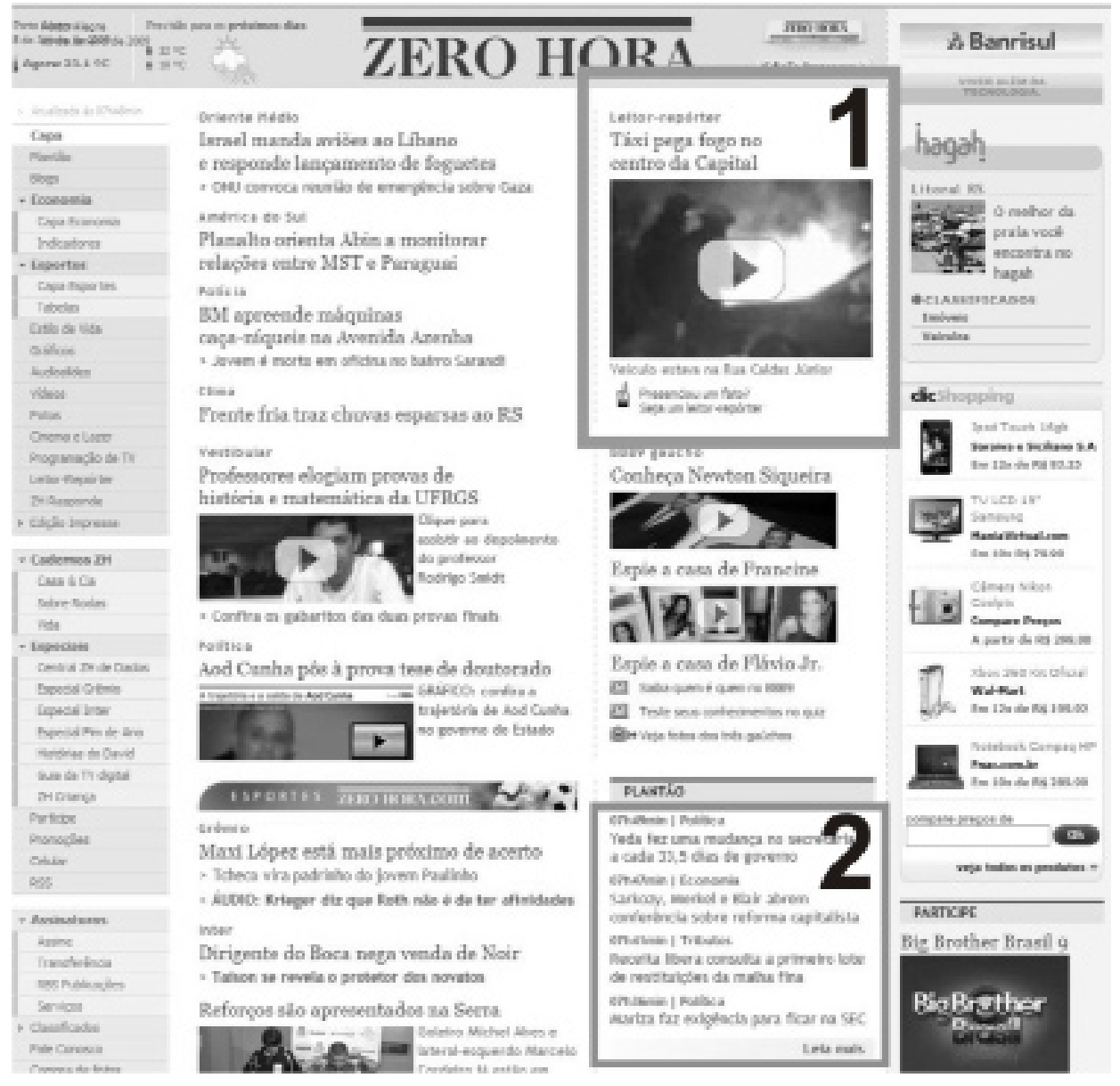

Figura 2 - A manchete (quadro de número um) aparece com destaque no topo da página e as chamadas (quadro dois) são mais discretas e aparecem em espaços menos privilegiados da capa ${ }^{15}$.

A pesquisa também notificou as chamadas que convidam os interagentes para o envio de fotografias e o número de chamadas para os blogs. A tabela a seguir mostra os resultados gerais da observação:

Tabela 1 - Número de chamadas gerais e de chamadas entre as manchetes.

\begin{tabular}{|l|c|c|}
\hline CHAMADAS & $\begin{array}{c}\text { NÚMERO DE } \\
\text { CHAMADAS GERAIS }\end{array}$ & $\begin{array}{c}\text { NÚMERO DE CHAMADAS } \\
\text { ENTRE AS MANCHETES }\end{array}$ \\
\hline Leitor-Repórter & 09 & 06 \\
\hline Murais & 90 & 23 \\
\hline Fotografias & 61 & 07 \\
\hline Blogs & 82 & 01 \\
\hline
\end{tabular}

Conforme a tabela 1, em nove capas foram identificadas chamadas para o Leitor-Repórter. Destas, seis apareceram entre as manchetes jornalísticas. Ao todo, quatro são manchetes que remetem aos conteúdos da seção colaborativa. Duas chamadas foram localizadas na parte inferior da capa, recebendo menor destaque na publicação. 
Já os convites complementares às manchetes principais, expostas no topo da página, apareceram em duas ocasiões, solicitando o envio de notícias e de fotos e vídeos.

Um total de 90 chamadas para os murais foi identificado nas capas, sendo que 67 estavam localizadas na parte inferior da interface, ou na coluna da direita do jornal digital, que é destinada aos espaços de variedades. As chamadas conduziam os interagentes à participação em debates e discussões. Todas as vezes em que os murais foram associados às manchetes jornalísticas, coletavam depoimentos dos interagentes sobre os assuntos das notícias. Assim, o jornal digital consegue expandir a abrangência da sua cobertura jornalística, isto é, o veículo amplia a quantidade de informações a respeito dos fatos transformados em notícia.

Com relação aos canais de publicação de fotografias, foram verificados sete casos de chamadas-convite relacionadas às pautas jornalísticas. A maioria remete à seção Leitor-Repórter, onde as imagens são publicadas. As demais chamadas para o envio de fotografias tem como tema o cotidiano dos interagentes.

Foram encontradas 82 chamadas para a leitura dos blogs. A maioria apresenta conteúdos dos profissionais do Grupo RBS. Portanto, tais espaços não privilegiam a publicação de conteúdos colaborativos. Apenas um blog amador foi destacado entre as manchetes das 96 capas.

Conforme o exposto, percebe-se que os conteúdos da seção LeitorRepórter e os murais apareceram com considerável frequência na amostra observada, complementando os dados jornalísticos. Neste artigo, serão descritos dois casos que demonstram tal utilização.

A imagem a seguir mostra um exemplo da utilização dos murais:

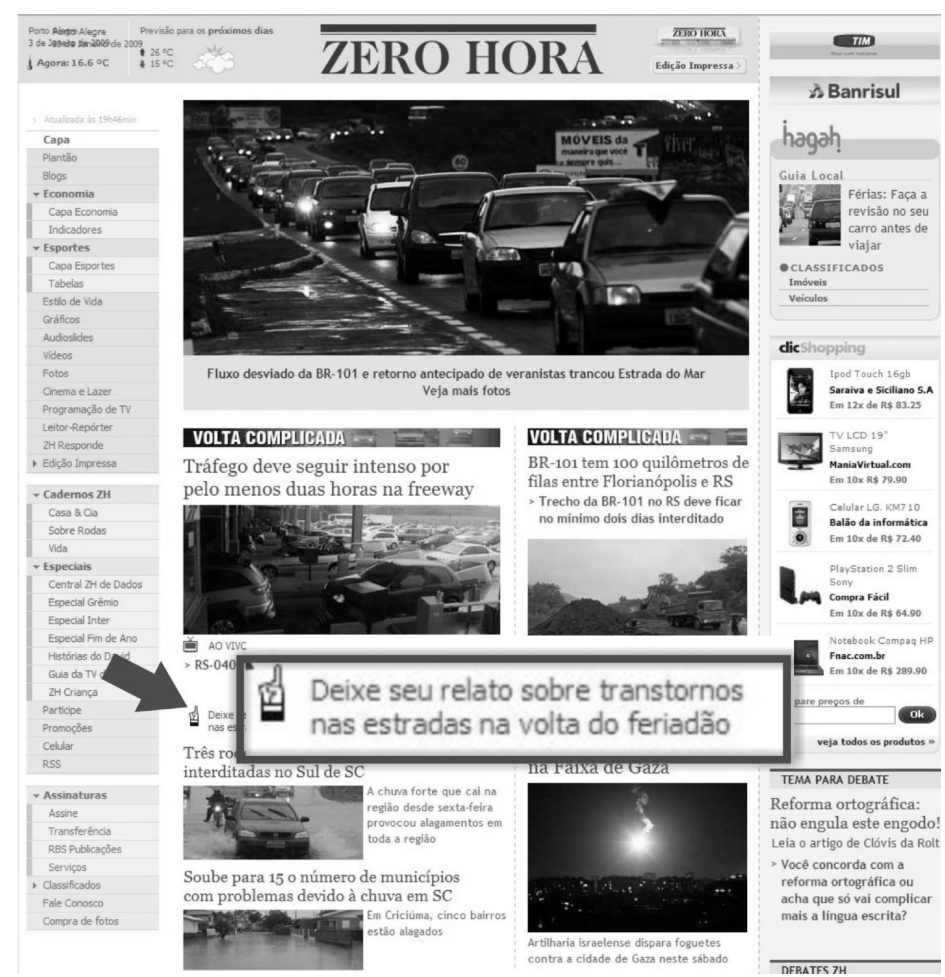

Figura 3 - No dia 3 de janeiro, Zero Hora.com pediu que o público enviasse relatos sobre o trânsito na volta do litoral pela freeway ${ }^{16}$.

${ }^{16} \mathrm{http}: / / w w w . c l i c r b s . c o m . b r /$ zerohora. 
Na figura 3, a flecha indica o link "Deixe seu relato sobre transtornos nas estradas na volta do feriadão", postado junto com a manchete principal da página, intitulada como "Tráfego deve seguir intenso por pelo menos duas horas na freeway". Percebe-se que, entre as intervenções da redação e os recursos de interação com as fontes, é estimulada a troca de informações entre jornalistas e interagentes. O retorno da chamada evidencia ainda mais o processo, como pode ser observado na capa do dia 4/01/2009:

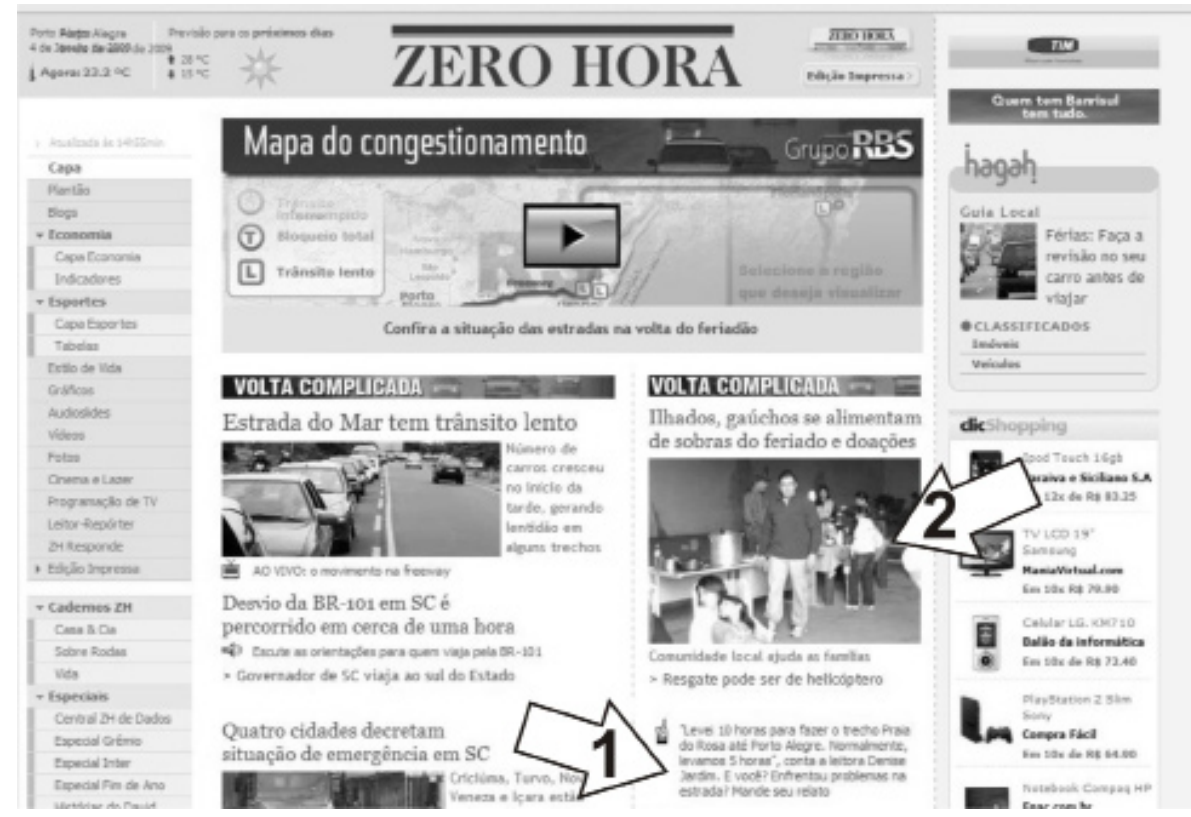

Figura 4 - Em 4 de janeiro, foram publicados os retornos dos interagentes para as chamadas da capa de 3 de janeiro ${ }^{17}$.

A flecha de número um aponta para o depoimento de uma motorista que teve problemas no trânsito do litoral catarinense até Porto Alegre. Junto com o relato da colaboradora está a frase "E você? Enfrentou problemas na estrada? Mande seu relato”. A flecha de número dois mostra uma fotografia enviada por uma colaboradora e postada na manchete "Ilhados, gaúchos se alimentam de sobras do feriado e doações". A chamada é referente a uma matéria construída pela redação. $\mathrm{O}$ uso da fotografia captada por uma amadora foi informado no corpo da notícia.

Os dados destacados indicam que os jornalistas de Zero Hora.com utilizam o que é enviado pelos interagentes na complementação das suas coberturas. No caso descrito agora, percebeu-se a tentativa de dar mais credibilidade à notícia, na capa, a partir do relato da colaboradora. Os conteúdos captados a partir dos convites feitos aos colaboradores são reunidos por determinado período, até que a redação formule novas matérias utilizando tais informações. Assim, criam-se expectativas sobre a publicação do que é encaminhado pelo público, ao mesmo tempo em que o veículo faz uma cobertura mais completa dos fatos.

A utilização dos materiais enviados à seção Leitor-Repórter também demonstra a valorização dos conteúdos amadores em Zero Hora.com. A imagem que segue traz um exemplo:

${ }^{17}$ http://www.clicrbs.com.br/ zerohora. 


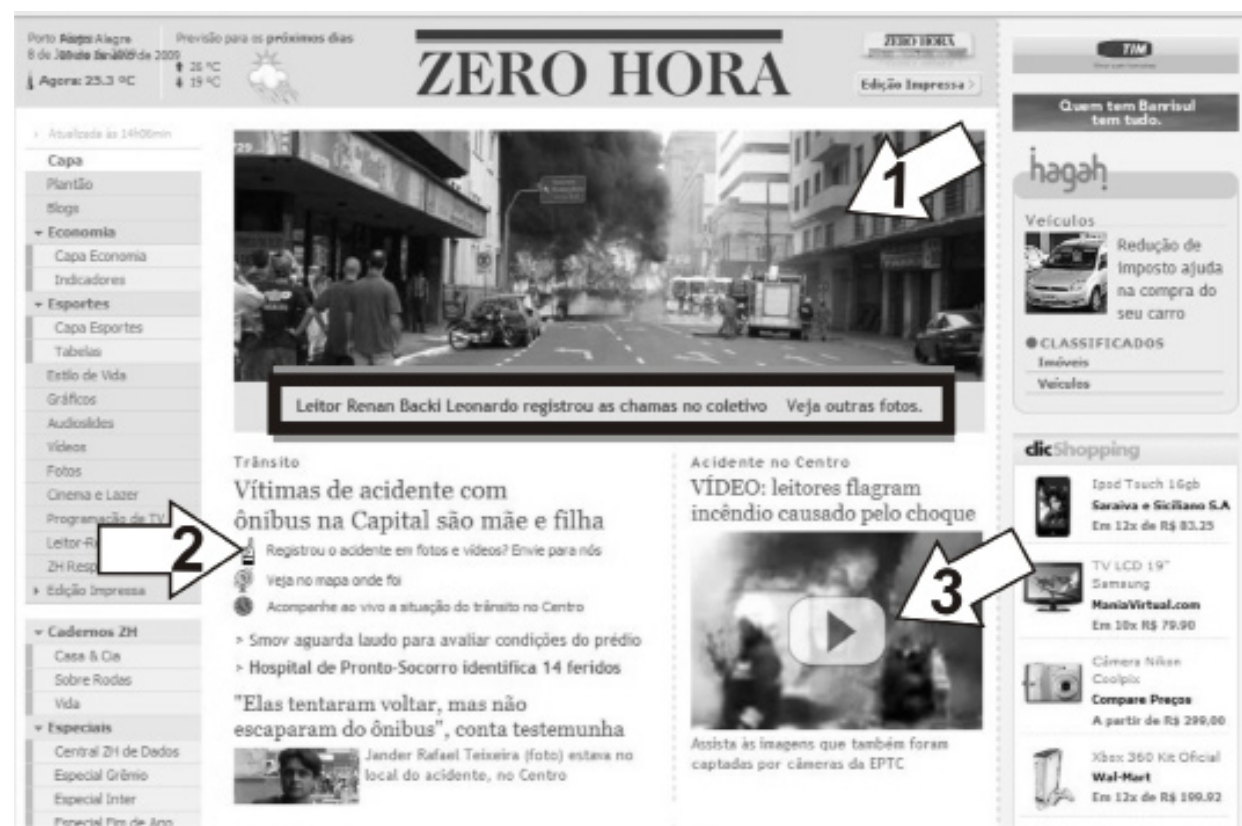

Figura 5 - A capa do dia 8 de janeiro de 2009 teve várias manchetes para os conteúdos publicados na seção Leitor-Repórter ${ }^{18}$.

$\mathrm{Na}$ figura 5, a flecha de número um aponta para uma das fotografias coletadas por interagentes que presenciaram o acidente com o ônibus do transporte coletivo urbano de Porto Alegre, registrado na manhã do dia 8/01/2009. A imagem mostra o momento em que o veículo foi tomado pelas chamas em pleno centro da capital gaúcha. Trata-se de uma situação inesperada, que representou perigo aos moradores e transeuntes.

O quadro preto destaca a legenda "Leitor Renan Backi Leonardo registrou as chamas no coletivo. Veja outras fotos". Clicando no link, os interagentes conferiam um slide show com diversas fotos tiradas por colaboradores e enviadas à redação de Zero Hora.com. No caso relatado, o jornal digital realizou uma ação parecida com o que foi feito no episódio do trânsito lento na freeway. Postou convites na capa do jornal digital solicitando que o público enviasse fotos, vídeos e textos (a flecha de número dois indica um desses links). O resultado foram 13 textos enviados ao Leitor-Repórter, alguns com vídeos e outros com fotografias. Assim, Zero Hora.com teve condições de mostrar vários ângulos do acidente com a ajuda dos interagentes. A flecha de número três mostra a chamada para um vídeo do incêndio, registrado por um colaborador.

\section{Considerações finais}

Os dados expostos reforçam a ideia de que os conteúdos colaborativos utilizados na página Zero Hora.com são misturados aos conteúdos jornalísticos quando oportuno. O jornal digital dá destaque para os conteúdos amadores entre as suas manchetes. A abertura acontece de forma moderada, porém confirma que o meio se apropria dos materiais dos leitores para enriquecer o seu produto. Marca disso são os convites para a colaboração em discussões temáticas,

${ }^{18} \mathrm{http}: / / w w w . c l i c r b s . c o m . b r /$ zerohora. 
com assuntos pré-definidos pela equipe do jornal digital. Em alguns momentos, o retorno destes convites é surpreendente, como constatado no caso do ônibus urbano que incendiou em Porto Alegre.

Percebeu-se a realização regular de convites para a participação do público. O processo não serve apenas à discussão de assuntos sem relevância jornalística: os leitores são estimulados a colaborar sempre que ocorre algum evento que transcende a capacidade de cobertura de Zero Hora.com. Assim, a utilidade da seção Leitor-Repórter e dos murais evolui de estratégia comunicacional que visa ampliar os acessos da página para uma parceria com os colaboradores. Eis um sinal de que o Pro-Am acontece no jornal digital, alargando as fronteiras do seu território. A inclusão de conteúdos colaborativos na capa de Zero Hora.com é considerada uma das linhas de fuga características da desrreterritorialização, já que se mescla, no jornal digital, a atuação de jornalistas e amadores, e ambos acabam trabalhando em parceria.

Cabe ressaltar que a des-re-territorialização não acontece de forma plena no caso de Zero Hora.com. Ocorre, no meio, a abertura moderada à participação do público, fator que demonstra uma transformação conservadora. Tal aspecto foi identificado nas capas observadas, já que as colaborações exibidas com destaque no espaço abordam temas referentes às pautas definidas previamente por sua equipe de jornalistas. Isso mostra que os profissionais continuam buscando o controle da situação comunicativa. Também é notório o destaque conferido às informações que atendem aos critérios de importância pertinentes ao jornalismo tradicional.

A partir dos dados expostos, constatou-se que ainda não é possível afirmar que a desrreterritorialização, ou a ruptura, está acontecendo. Contudo, as suas marcas são visíveis. O campo está em crise, a partir do surgimento de diferentes possibilidades de ação no ciberespaço, que provocam o alargamento das suas fronteiras. Assim, destaca-se a importância de verificar a possibilidade do Pro-Am em outros jornais de referência e, também, nos demais sites informativos.

\section{Referências}

ANDERSON, C. A Cauda Longa: do mercado de massa para o mercado de nicho. Rio de Janeiro, Elsevier, 2006.

BARBOSA, S. Jornalismo Digital em Base de Dados (JDBD) - Um paradigma para produtos jornalísticos digitais dinâmicos. Tese de Doutorado (UFBA). Salvador, 2006.

BELOCHIO, V. A Cauda Longa da Informação e suas Implicações no Jornalismo: Estratégias Comunicacionais, Remediação e Des-re-territorialização. Artigo apresentado no 6 ${ }^{\circ}$ SBPJor. São Bernardo do Campo, 2008.

BELOCHIO, V. Jornalismo Colaborativo em Redes Digitais: Estratégia Comunicacional no Ciberespaço. O caso de Zero Hora.com. Dissertação de mestrado na UFSM. Santa Maria/RS, 2009.

Estudos em Jornalismo e Mídia - Ano VI - n. 2 pp. 203 - 216 jul./dez. 2009 
BERGER, C. L. Campos em confronto: jornalismo e movimentos sociais. As relações entre o movimento sem terra e a Zero Hora. Tese de Doutorado (USP). São Paulo, 1996.

BERGER, P.; LUCKMANN, T. A construção social da realidade. Tradução de Floriano de Souza Fernandes. $13^{a}$ ed. Petrópolis: Vozes, 1985.

BOLTER, J. D.; GRUSIN, R. Remediation: Understanding New Media. Cambridge, The MIT Press: 2000.

BRIGGS, M. Jornalismo 2.0. Como sobreviver e prosperar. Um guia de cultura digital na era da informação. Jan Schaffer, Editor, 2007.

BRIGGS, A.; BURKE, P. Uma história social da mídia: de Gutenberg à internet. Rio de Janeiro: Jorge Zahar, 2004.

CASTELLS, M. A sociedade em rede: A era da informação: economia, sociedade e cultura. Volume 1, São Paulo: Editora Paz e Terra, 2a. ed., 1999.

ECHEVERRÍA, J. Los Señores del aire: Telépolis y el Tercer Entorno. Barcelona: Ediciones Destino, 1999.

FIDALGO, A. Sintaxe e semântica das notícias online: para um jornalismo assente em base de dados. In: http://www.bocc.ubi.pt/pag/_texto. php3?html2=fidalgo-jornalismo-base-dados.html. Universidade Beira do Interior, 2004.

GILLMOR. D. Nós, os media. Lisboa: Presença, 2005.

LEMOS, A. Ciberespaço e tecnologias móveis: processos de territorialização e desterritorialização na Cibercultura. Artigo apresentado no $15^{\circ}$ Encontro Anual da Compós. Bauru, 2006.

Mídia Locativa e Territótios Informacionais. Congresso Brasileiro de Ciências da Comunicação - XVI COMPÓS: Curitiba/PR, 2007.

Ciberespaço e Tecnologias Móveis. Processos de Territorialização e Desterritorialização na Cibercultura. Artigo da pesquisa Cibercidades (CNPq). Acesso no endereço <http:/www.facom.ufba.br/ciberpesquisa/andrelemos>.

LEMOS, A.; CUNHA, P. (orgs). Olhares sobre a Cibercultura. Sulina, Porto Alegre, 2003.

LÉVY, P. Cibercultura. $2^{\mathrm{a}}$ ed. São Paulo: Ed. 34, 2000.

MACHADO, E. O ciberespaço como fonte para os jornalistas.

MIELNICZUK, L. Jornalismo na web: Uma Contribuição para o Estudo do Formato da Notícia na Escrita Hipertextual. Tese de Doutorado desenvolvida na UFBA. Salvador, 2003.

NOCI, J. D.; SALAVERRÍA, R. Manual de Redacción Ciberperiodistica. Editorial Ariel, S. A., Barcelona, 2003.

ORTIZ, R. Espaço e territorialidade. In: ORTIZ, Renato. Um outro território: ensaios sobre a mundialização. São Paulo, SP: Olho d'Água, 1999.

PINTO, M. Fontes jornalísticas: contributos para o mapeamento do campo. Comunicação e Sociedade 2, Cadernos do Noroeste, Série Comunicação, 2000. PRIMO, A. Interney blogs como micromídia digital: Elementos para o estudo do encadeamento midiático. In:17Compós. São Paulo. Anais, 2008.

PRIMO, A.; TRÄSEL, M. Webjornalismo participativo e a produção aberta de notícias. Contracampo (UFF), 2006.

ROMANÍ, C. C.; KUKLINSKI, H. P. Planeta Web 2.0. Inteligencia colectiva o 
medios fast food. Grup de Recerca d'Interaccions Digitals, Universitat de Vic. Flacso/México.Barcelona/México DF, 2007.

SAAD, B. Estratégias para a mídia digital. Editora Senac. São Paulo, 2003.

SILVA, F.F. Jornalismo live streaming: tempo real, mobilidade e espaço urbano. Artigo apresentado no $6^{\circ}$ SBPJor. São Bernardo do Campo, SP, 2008.

STORCH, L. A leitura ativa no jornalismo online: o fenômeno da interação hipertextual na organização da participação jornalística. Artigo apresentado no $6^{\circ}$ SBPJor. São Bernardo do Campo, SP, 2008.

THORNTON, S. Club Cultures. Hannover: Wesleyan University Press, 1996.

Recebido em 21 de agosto de 2009

Aprovado em 19 de outubro de 2009 